\title{
How to Delineate the General Profiles of Functionality of Citizen's Aged 65 Years and Old as a Function of Its Age
}

\author{
Maria Goes ${ }^{1}$, Manuel Lopes ${ }^{2}$, Henrique Oliveira ${ }^{3}$, João Marôco ${ }^{4}$, César Fonseca $^{2}$, \\ Margarida Santos ${ }^{5}$, and José Caeiro ${ }^{6}$
}

\author{
${ }^{1}$ Escola Superior de Saúde, Instituto Politécnico de Beja, Beja, Portugal \\ 2 Escola Superior de Enfermagem de São João de Deus, Universidade de Évora, Évora, Portugal \\ 3 Instituto de Telecomunicações, IST Torre Norte, Piso 10, Av. Rovisco Pais, Lisbon, Portugal \\ ${ }^{4}$ Instituto Universitário de Ciências Psicológicas, Sociais e da Vida, Lisbon, Portugal \\ ${ }^{5}$ Escola Superior de Medicina Tradicional Chinesa, Lisbon, Portugal \\ ${ }^{6}$ Instituto de Engenharia de Sistemas E Computadores, INESC-ID, Lisbon, Portugal
}

\begin{abstract}
Objectives: A core set of International Classification of Functioning, Disability and Health codes was used, to ascertain the general profile of function-ality as a function of biological and sociodemographic characteristics, notably the age of the citizens.

Methods: Data were collected by health professionals in the participants' houses. The factorial validity of the construct was assessed by a confirmatory factor analysis. An ordinal regression model was built to identify the general profile of functionality as a function of age.

Results: It is expected that people under the age of 74 years will present no functional problems and that, after age 74, the most likely functionality problem will be a "MILD problem".

Discussion: The functional profile of each elderly is interrelated with his or her sociodemographic context as well as with the overarching biological, cultural, and environmental characteristics of society. A progressive decrease in GPF occurs with age.

Conclusions: The evaluation of each person (even those with no perceived or incipient levels of functional impairment who are at risk of progressing to a more severe disability) about what are the factors that are related with this functional decline as people get older, allows identify the respective nursing interventions to be developed.
\end{abstract}

Keywords: Ageing · Elderly residing in the community $\cdot$ Functionality profile assessment $\cdot$ Confirmatory factor analysis · Nursing care

\section{Introduction}

At the population level, Portugal (a country at southwestern Europe) has one of the highest rates of aging index of the resident population among the European Union 
countries, (153.2 elderly per 100 young) [1], and national estimates indicate that this rate will more than double by 2080 (317 elderly for every 100 young) [2]. The Baixo Alentejo region (BAR), which covers an area of $8.544 .6 \mathrm{~km}^{2}$ (corresponding to $10.8 \%$ of the main territory), is an inland region located at middle south of the Portugal that borders Spain (Estremadura region). It was chosen for this study because it undergoes a delicate, worrying and heterogeneous socio-demographic scenario of population aging [3]: (i) since rural areas prevail to a larger extend (traveling average distances between villages range from $20 \mathrm{~km}$ to $120 \mathrm{~km}$ ); (ii) the public transportation network in BAR is scarce and inefficient, thus causing some mobility inequalities along the territory, including some cases where people is unable to travel by their own means (e.g. due to their advanced age some elderly are no longer allowed to drive and presenting disabilities); (iii) it has the lowest population density of the country (14.8 individual per $\mathrm{Km}^{2}$ ) [4]; (iv) it is identified as an aged region, presenting an important aging index of 189.2 elderly per 100 young [5]; and (v) most of these people they live alone or with other elderlies, often playing the role of caregivers.

As elderly get older, they become increasingly fragile, presenting functional impairments, multimorbidity and a significant prevalence of chronic conditions that easily decompensate them, most commonly seen in the only reference Emergency Department (ED) at BAR for medical problems such as cardiac, respiratory, and cerebrovascular related conditions (generally related to self-care problems), but also have a high rate of fall-related injuries [6, 7]. A report made by the Health General Directorate of the Portuguese Health Service, state that the burden of chronic disease in Portuguese population is estimated as follows: (i) $18 \%$ of the Portuguese health system users have one chronic disease; (ii) $11 \%$ has 2 ; (iii) $8 \%$ has 3 ; (iv) $22 \%$ has 4 or more. Therefore, at least $59 \%$ of people present one or more chronic disease (estimate) [8]. Due to the complexity and heterogeneity of individual aging, the level of functionality may vary distinctly from person to person. Studying the individual aging by integrating a care model in continuity and proximity that allows elderlies and family caregivers to monitor and manage their health at home, always under the supervision of health professionals, which may result in management of various chronic conditions (multimorbidity) as well as provide a "safety net" before a health crisis requiring ED care occurs [6, 7], was the main motivation that led the authors to develop the present study [3]. To achieve this goal, promoting the quality of life related to the elderly's health, by requalifying their potential and allowing them to live with more independence and autonomy, it is essential. According to Lesende et al., the health care of patients with multimorbidity and the appropriate strategies of interventions have a better outcome if structured based on a previous evaluation of the functional state of the person [9].

By providing multidisciplinary interoperability, the World Health Organization (WHO) has developed several tools in an attempt to devise a standardized international health information system. One example is the International Classification of Functioning, Disability, and Health (ICF) [10]. This classification encompasses "biopsycho-socio-environmental" factors because it classifies (i) the functioning, disability, and health of people as an interrelationship among health states; (ii) bodily functions and structures (i.e., the presence or absence of disabilities); (iii) activity (i.e., the performance of a task or action by an individual); (iv) participation (i.e., the involvement of 
an individual in a real-life situation); and (v) contextual (i.e., environment and personal) factors that can act as "barriers" or "facilitators" [11-13].

In Portugal, Lopes [14] and then Fonseca [15] developed a tool to evaluate the individual profile of functionality of people aged 65 and over, called the Elderly Nursing Core Set (ENCS), which resulted in a set of 31 ICF codes, hereon referred to as "ENCS31".

Since the previous research tool was only developed to institutionalized elderlies, the authors of the present research intend to proceed with the previous study [16], by applying the ENCS31 to people aged 65 or over residing in the community, aiming the following objectives: (i) validate an experimental factorial model through a confirmatory factor analysis (CFA); (ii) a descriptive statistics of biological and sociodemographic variables, as well as the respective proportion of general profiles of functionality (GPF); (iii) standardizing the GPF based on age.

\section{Methods}

\subsection{Subjects}

This study examined the population aged 65 years or older who were registered in the Portuguese Health System of BAR, namely the Local Health Unit of Baixo Alentejo (ULSBA, for its acronym in Portuguese) [17]. The sample size was calculated adopting the formulae proposed by Scheaffer et al. [18], stratified by gender (male and female) and age group (65 to 74,75 to 84,85 or more years), adopting the Neyman optimal allocation, based on the total of elderlies listed in the ULSBA's database (32893). The calculated sample size was 470 elderlies, which were randomly selected from the respective ULSBA's database. The inclusion criteria cumulatively adopted were: (i) age 65 years or older; (ii) desire to participate in the study; (iii) residing in the BAR in their own home or in the home of family members or friends; and (iv) able to make their own decisions, even if sick or hospitalized. The final (random) sample, stratified by gender (male and female) and by age range (65 to 74,75 to 84,85 or more years), included 351 people who, cumulatively, fulfilled all the inclusions criteria, signed an informed consent document and answered to all the ENCS31's questions.

Data were collected between January 2016 and April 2017 at the homes of participants by health teams from ULSBA using the ENCS31. Prior to each interview, each health professional presented the informed consent document (which was especially developed for this study and previously approved by the ethics committee of ULSBA) to each individual and his or her family. During this period, the informed consent document was fully read by the individual in the presence of the health professional or it was read by the health professional if the individual was unable to read it. Information about the study objectives were fully provided to the individuals and their families, stating that their confidentiality and anonymity would be guaranteed. The interviews took at least 30 to $45 \mathrm{~min}$, depending on the elderly's age and their level of literacy, and they started only after the elderly had agreed to participate in the study and had freely signed the informed consent. However, at any time each individual was allowed to cancel the interview based on his own initiative. 


\subsection{Statistical Procedures}

After validating all collected data, a database was prepared using the IBM SPSS for Windows, Version 23.0 (IBM, Armonk, NY).

A previous Principal Component Analysis allows us to extract five latent factor based on Kaiser criteria, selecting a possible factorial structure, which in our case result in 5 latent factors composed of a total of 25 ICF codes. After that, descriptive analysis was used to describe the biological and sociodemographic variables of the sample data, as well as the GPF scores of the 25 ICF codes.

The factorial validity of this new subset of ENCS31 was assessed through a CFA using SPSS AMOS version 23.0.0 (IBM, Armonk, NY) and according to Marôco [19]. The CFA applied the following steps: (i) construct reliability was evaluated using Cron-bach's alpha $(\alpha)$ and composite reliability (CR) as an alternative measure, and both measures were obtained for each of the five latent factors; and (ii) construct validity was evaluated using an analysis of the factor weights of the model (factorial validity), the average variance extracted (AVE) for each latent factor (convergent validity), and the comparison with the squared correlation coefficients between the latent factors (discrim-inant validity). Because the maximum likelihood method was used to estimate the CFA model parameters, the assumption of normality was tested by analyzing the skewness and kurtosis values. The overall goodness-of-fit of the model was assessed based on the indexes suggested by Marôco [19]. The codes with the highest weight in the esti-mation of the scores of the latent factors were identified through an analysis of factor score weights (FSWs). Finally, the 25 extracted ICF codes are hereon designated as "ENCS25". In sum, six codes (b280, b420, b440, b445, b525, and s810) were removed.

An ordinal regression model was then performed to evaluate whether the age and gender of the respondents showed a significant effect on the GPF (which included the 25 validated codes). That analysis sought to answer the following research questions: "Is the GPF identical between men and women?" "What is the effect of Age?"

\section{Results}

\subsection{Confirmatory Factor Analysis}

The five latent factors were thematically characterized by the authors, based on content of WHO ICF practical manual an WHO ICF checklist documents [20, 21], as follows:(i) "Self-care in activities of daily living" - SC-ADL; (ii) "Self-care in fundamental human needs" - SC-FHN; (iii) "Mental functions" - MF; (iv) "Communication" - COM;(V) "Support and relationships" - SR. The reliability of each latent factor was evaluated based on Cronbach's $\alpha$, whose values ranged from "very good" to "reasonable", except for the latent factor SR ( $<0.60$ but very close to the threshold for "Weak") (Table 1).

The ENCS25 was subjected to a CFA (see Fig. 1). The initial model showed a "fair"

quality (performed without correlating the measurement error of any codes belonging to ENCS31): (i) $\chi^{2} / d f=4.820$ (Chi-squared statistics divided by the degrees of freedom);(ii) $C F I=0.837$ (Comparative fit index); (iii) $P C F I=0.739$ (Parsimony comparative fit index); (iv) $G F I=0.757$ (Goodness-of-fit index); (v) $P G F I=0.617$ (Parsimony goodness-of-fit index) (vi) $R M S E A=0.104$ (Root mean square error of approximation); 
Table 1. List of five retained latent factors with the respective reliability results, eigenvalues and percentages of variance explained.

\begin{tabular}{l|l|l|l|l|l}
\hline \multirow{2}{*}{ ICF codes } & \multicolumn{4}{l}{ Latent factors } & \multicolumn{4}{l}{$l$} \\
\cline { 2 - 6 } & SF-ADL & SF-FHN & MF & COM & SR \\
\hline Eigenvalue & 9.749 & 1.606 & 2.156 & 1.438 & 1.129 \\
\hline Variance explained & $39.0 \%$ & $6.4 \%$ & $8.6 \%$ & $5.8 \%$ & $4.5 \%$ \\
\hline Cronbach's alpha & $\begin{array}{l}\alpha=0.924 \\
\text { (Very Good) }\end{array}$ & $\begin{array}{l}\alpha=0.779 \\
\text { (Reasonable) }\end{array}$ & $\begin{array}{l}\alpha=0.848 \\
\text { (Good) }\end{array}$ & $\begin{array}{l}\alpha=0.853 \\
\text { (Good) }\end{array}$ & $\begin{array}{l}\alpha=0.580 \\
\text { (Almost } \\
\text { Unallowable) }\end{array}$ \\
\hline
\end{tabular}

(vii) PCLOSE $<0.001$ (" $p$ value" for testing the null hypothesis that RMSEA is less than .05 in the population); and (viii) $M E C V I=4.020$ (Mean expected cross-validation index). However, after correlating the measurement errors of codes $\mathrm{d} 450$ with $\mathrm{d} 465, \mathrm{~d} 410$

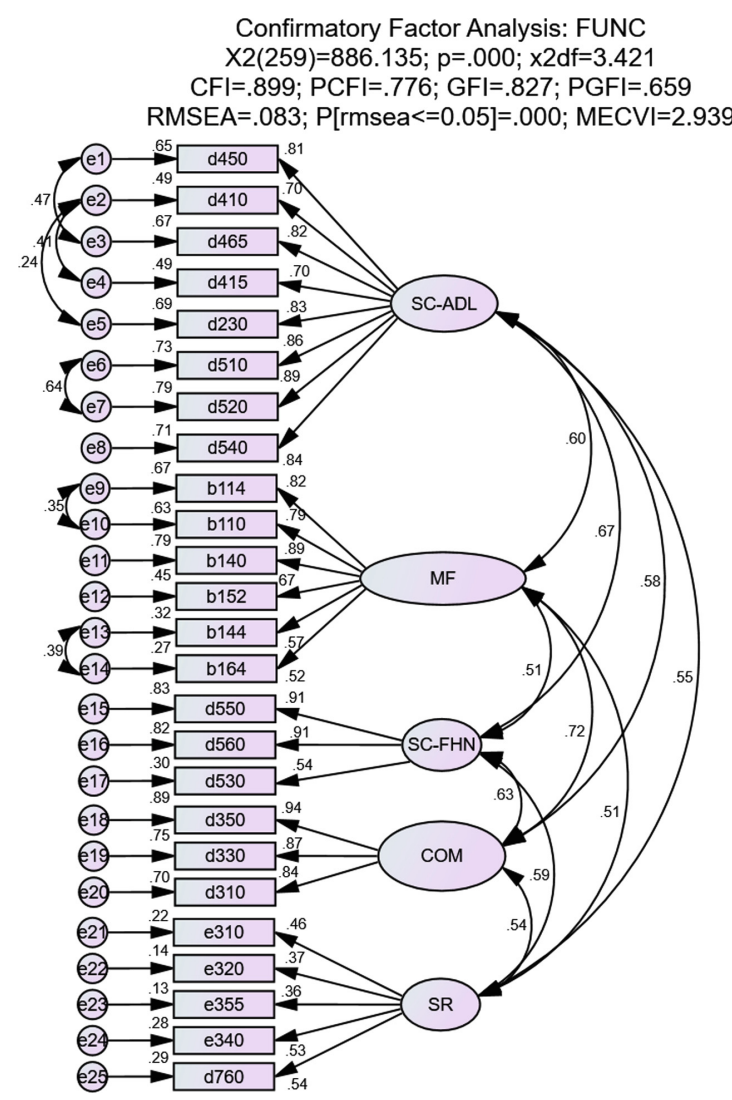

Fig. 1. The fitted factorial model of the ENCS25, after correlating the measurement errors of codes whose MIs suggested a correlation (empirically adopted MI > 15). 
with $\mathrm{d} 415$ and d230, d510 with d520, b114 with b110 and finally between b144 and 164, as suggested by the modification indices (MIs > 15), the overall model goodness-of-fit was classified as "fair to good" (see the qualitative classification of Table 4.1 in Marôco) [19]. Figure 1 shows the adjusted model with the new CFA indexes at the top.

Of the 25 standardized factor weights, only two (12\%) presented values lower than 0.5 , which suggested that the factorial validity of the construct is considered as "Favorable". The convergent validity was evaluated using the composite reliability measure (CR) (an alternative to Cronbach's alpha as suggested by Marôco [19]), based on the results from the CFA and the convergent validity $(\mathrm{CV})$, this last characteristics being evaluated by the average variance extracted of the CFA model (AVE) [19]. Regarding $\mathrm{CR}$, all values were greater that 0.8 (considered an appropriated reliability of the construct, since the value is higher than 0.7, as suggested by Marôco [19]), except for the SR latent factor $(C R=0.564)$, although values less than 0.7 may be accepted in case of exploratory research [22], which was the case of the present paper. In relation to CV, the AVE values were always greater than 0.5 , representing an adequate convergence validity as suggested by Marôco [19], although a "weak" (AVE = 0.210) value was achieved, again for the SR latent factor (an expected result since this latent factor includes three standardized regression weights lower than 0.5 , as can be seen in the bottom of Fig. 1).

\subsection{Biological and Sociodemographic Variables and GPF}

The sample data exhibited a higher proportion of women than men (Table 2). Most respondents were married and a considerable proportion was widowers (32.5\%: 76.3\% of women and $23.7 \%$ of men). Regarding education level, the eight categories listed were reduced to four because of the small absolute frequency observed in the higher education levels, where approximately half of the respondents $(46.4 \%=29.6 \%+16.8 \%)$ did not had formal education, and $29.6 \%$ of the sample (57.8\% of women and $42.2 \%$ of men) were illiterate. A quick review of the general profiles of functionality showed that the largest proportion of the "no problem (0-4\%)" profile corresponded to individuals in the younger group and those with a higher education level. The most common profile observed was "mild problem (5-24\%)" for almost all other variables (numbers typed in bold in Table 2).

\subsection{Standardizing the GPF Based on Age and Sex}

To evaluate whether the age and gender of respondents had a significant effect on the GPF, an ordinal regression model was done. The results showed that gender was not significant in the model: (i) $b_{\text {Gender }}=0.045$, with $p=0.750$ and the $95 \%$ confidence interval (CI) equal to $\mathrm{CI}=[-.234, .325]$; and (ii) $b_{A g e}=0.074$, with $p<0.001$ and $\mathrm{CI}=[.055, .093]$; thus, no statistical evidence supports the hypothesis that the GPF differs between men and women. The model was reproduced again only for age. The final model was considered as highly significant $\left(-2 L L=193.832, \chi^{2}(1)=64,347\right.$, $p<0.001)$, although the effect size was somewhat small $\left(R_{C S}^{2}=0.168 ; R_{N}^{2}=0.195\right.$; $\left.R_{M F}^{2}=0.093\right)$. In the ordinal regression model, the link function "Log-negative log" $P(Y<K)=\exp \left(-\exp \left(-\left(b_{K}-b_{\text {Age }} \times A g e\right)\right)\right)$ was adopted because it is recommended when the classes of the lowest-order dependent variable (functional profiles 
Table 2. This table lists the biological and sociodemographic characteristics of the 351 respondents residing in the BAR as well as the respective proportion of general profiles of functionality taken from the ENCS25.

\begin{tabular}{|c|c|c|c|c|c|c|c|}
\hline \multirow[t]{2}{*}{ Variables } & \multirow[t]{2}{*}{$n$} & \multirow[t]{2}{*}{$\%$} & \multicolumn{5}{|c|}{ General Profile of Functionality } \\
\hline & & & $\begin{array}{l}\text { No } \\
0-4 \%\end{array}$ & $\begin{array}{l}\text { Mild } \\
\text { 5-24\% }\end{array}$ & $\begin{array}{l}\text { Moderate } \\
25-49 \%\end{array}$ & $\begin{array}{l}\text { Severe } \\
50-95 \%\end{array}$ & $\begin{array}{l}\text { Complete } \\
96-100 \%\end{array}$ \\
\hline Gender: & - & - & - & - & - & - & - \\
\hline Male & 163 & 46.4 & $34.6 \%$ & $56.4 \%$ & $6.4 \%$ & $2.7 \%$ & $0.0 \%$ \\
\hline Female & 188 & 53.6 & $37.4 \%$ & $50.9 \%$ & $11.0 \%$ & $0.6 \%$ & $0.0 \%$ \\
\hline Age group: & - & - & - & - & - & - & - \\
\hline $65-74$ & 132 & 37.6 & $58.3 \%$ & $37.9 \%$ & $2.3 \%$ & $1.5 \%$ & $0.0 \%$ \\
\hline $75-84$ & 135 & 38.5 & $27.4 \%$ & $62.2 \%$ & $8.9 \%$ & $1.5 \%$ & $0.0 \%$ \\
\hline 85 and higher & 84 & 23.9 & $14.3 \%$ & $65.5 \%$ & $17.9 \%$ & $2.4 \%$ & $0.0 \%$ \\
\hline Marital status: & - & - & - & - & - & - & - \\
\hline Single & 27 & 7.7 & $25.9 \%$ & $59.3 \%$ & $14.8 \%$ & $0.0 \%$ & $0.0 \%$ \\
\hline Married & 206 & 58.7 & $42.2 \%$ & $49.5 \%$ & $6.3 \%$ & $1.9 \%$ & $0.0 \%$ \\
\hline Divorced & 4 & 1.1 & $0.0 \%$ & $100.0 \%$ & $0.0 \%$ & $0.0 \%$ & $0.0 \%$ \\
\hline Widowed & 114 & 32.5 & $28.1 \%$ & $\mathbf{5 8 . 8 \%}$ & $11.4 \%$ & $1.8 \%$ & $0.0 \%$ \\
\hline $\begin{array}{l}\text { Educational } \\
\text { level: }\end{array}$ & - & - & - & - & - & - & - \\
\hline $\begin{array}{l}\text { Does not know } \\
\text { how to read or } \\
\text { write }\end{array}$ & 104 & 29.6 & $12.5 \%$ & $65.4 \%$ & $18.3 \%$ & $3.8 \%$ & $0.0 \%$ \\
\hline $\begin{array}{l}\text { Knows how to } \\
\text { read and write }\end{array}$ & 59 & 16.8 & $28.8 \%$ & $62.7 \%$ & $6.8 \%$ & $1.7 \%$ & $0.0 \%$ \\
\hline $1^{\text {st }}-4^{\text {th }}$ grade & 165 & 47.0 & $46.1 \%$ & $49.7 \%$ & $3.6 \%$ & $0.6 \%$ & $0.0 \%$ \\
\hline More education & 23 & 6.6 & $87.0 \%$ & $8.7 \%$ & $4.3 \%$ & $0.0 \%$ & $0.0 \%$ \\
\hline
\end{tabular}

indicating a less severe problem) have a higher frequency when compared to the classes of severe and complete problems (presenting low frequencies) [19]. $b_{K}$ is the coefficient associated with each of the three thresholds obtained because no respondent showed a "complete problem" GPF $\left(b_{K=1}=5.718, p<0.001 ; b_{K=2}=8.138, p<0.001\right.$ and $\left.b_{K=3}=9.994, p<0.001\right)$. As age increases, the probability of observing response items that corresponded to a greater problem/severity functional profiles increased because the parameter estimate for age was positive $\left(b_{A g e}=0.074, p<0.001\right.$; see the curves in Fig. 2$)$. With regard to the GFI of the model, Pearson's chi-square and deviance tests revealed that the null hypothesis regarding the model fit was not rejected $\left(\chi_{\text {Pearson }}^{2}(98)=90.232, p=\right.$ 0.699 and $\left.\chi_{\text {Deviance }}^{2}(98)=79.202, p=0.918\right)$. The assumption of slope homogeneity was validated $\left(-2 \mathrm{LL}=191.031, \chi^{2}(2)=2.801, p=0.246\right)$. 


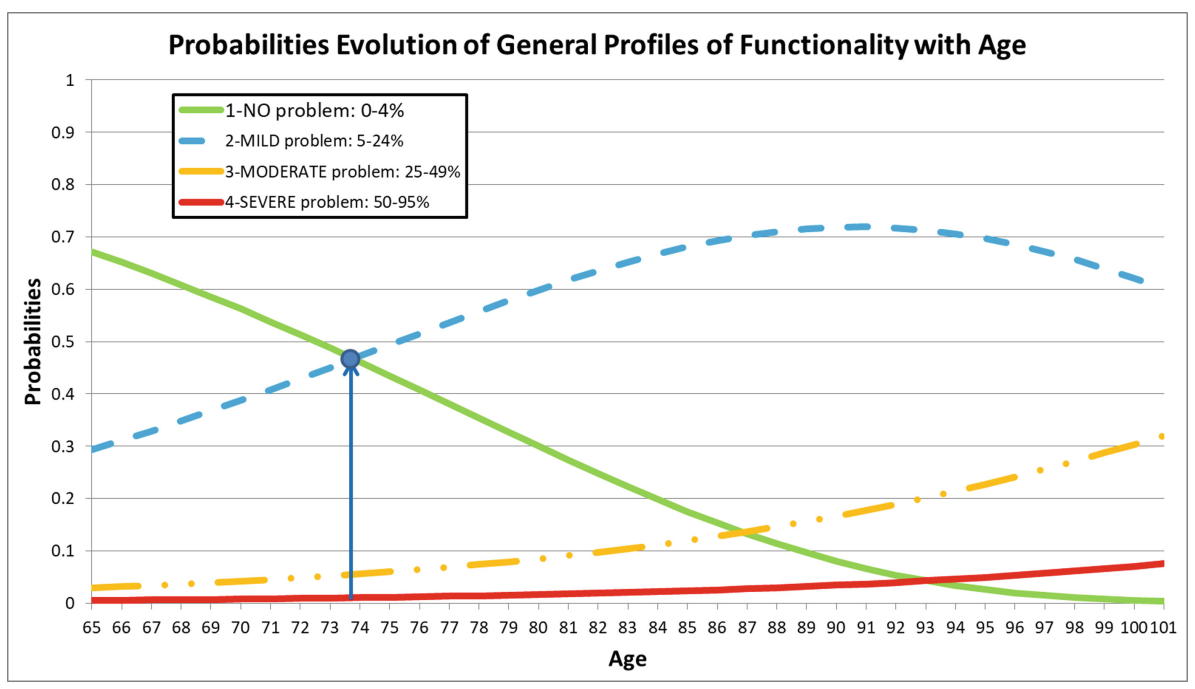

Fig. 2. Probabilities evolution regarding the general profiles of functionality, as a function of the age of the respondents.

\section{Discussion}

\subsection{Characterization of Biological and Sociodemographic Factors and GPF}

The functional profile of each elderly is interrelated with his or her sociodemographic context as well as with the overarching biological, cultural, and environmental characteristics of society; this aspect was there generally observed in the present study, which corroborates the reports of other authors $[23,24]$. The current sample followed the trend observed in the scientific literature; was a predominance of women, particularly in the older population group, a phenomenon known as the "feminization of old age" [25]. Table 2 shows that the functional profile "No problem (0-4\%)" had a greater proportion of the youngest participants, which has been observed by other studies [4]. The same is true of the people with the highest education levels because literacy helps people better and more effectively cope with their health/disease process (c.f., Kimberly Parr [26] and Abalo et al. [24]).

\subsection{Standardization of the GPF Based on Age}

Figure 2 suggests that the most likely GPF up to 74 years of age should be "no problem" and that "mild problem" should be the most likely profile after this threshold, with a progressive decrease in GPF with age. This result aligns with that found by Lopes et al. [13], Abalo et al. [24] and Lesende et al. [9]. These results answer the research question: "What is the effect of age on the GPF of people aged 65 and over who reside in the BAR?" Note that this question was reformulated because gender was not significant in the model. 


\section{Conclusions}

It is known that as people get older, they present functional decline due to the progressive increase of impairments and disabilities. The authors think that the evaluation of each person (even those with no perceived or incipient levels of functional impairment who are at risk of progressing to a more severe disability) about what are the factors that are related with this functional decline as people get older and identify the respective nursing interventions to be developed, based on the results shown in Fig. 2, will avoid the worsening in the patients' health status and the upward spiral in their care needs, which is potentially modifiable, predictable and manageable, leading them to achieve gains in autonomy and independence for self-care.

\section{Limitations}

This study presents the following limitations. The most important was the lower number of respondents (351 although expected 470), especially due the lower level of participation of some health professionals. Since this study has been focalized in a region of Portugal main territory that presents special demographic and geographic characteristics, results may not be necessarily generalized for other regions or even for the entire country.

Acknowledgements. The authors acknowledge all the support given by all the health professional that collaborate during the data acquisition, especially when donning all the interviews to all the persons belonging to the sample, as well as the professional support given by primary health care teams of ULSBA (http://www.ulsba.min-saude.pt/).

Funding. This work was supported by 4IE project (0045-4IE-4-P) funded by the Interreg V-A España-Portugal (POCTEP) 2014-2020 program.

\section{References}

1. PORDATA - The Database of Contemporary Portugal. Ageing index. https://www.pordata. pt/en/Europe/Ageing+index-1609. Accessed 3 Mar 2019

2. INE - Statistics Portugal. Projections of resident population in Portugal 2015 and 2080. https://www.ine.pt/xportal/xmain?xpid=INE\&xpgid=ine_destaques\&DESTAQUESdest_ boui=277695619\&DESTAQUESmodo=2\&xlang=en. Accessed 16 Mar 2019

3. Goes, M., Oliveira, H., Lopes, M.J.: Spatial analysis techniques applied to the characterization of elderly population for the planning of nursing care. RIASE - Revista Ibero-Americana de Salud Y Envejecimiento 2(3), 638-650 (2016). https://doi.org/10.24902/r.riase.2016.2(3).693

4. INE - Statistics Portugal: Population's density $\left(\mathrm{No} . / \mathrm{km}^{2}\right)$ by Place of residence (at the date of Census 2011). from (INE): https://www.ine.pt/clientFiles/bsXhOiSE4Vgv-1t8J_8qFeVt_ 22967.xls. Accessed 25 Jan 2019

5. INE - Statistics Portugal. Ageing ratio by place of residence, data reference period 2017. from (INE): https://www.ine.pt/clientFiles/ZABbysovUAa8_SgERrcmeKpY_23158. xls. Accessed 25 Jan 2019

6. Gruneir, A., Silver, M.J., Rochon, P.A.: Review: emergency department use by older adults: a literature review on trends, appropriateness, and consequences of unmet health care needs. Med. Care Res. Rev. 68(2), 131-155 (2011). https://doi.org/10.1177/1077558710379422 
7. Hsieh, V.C.-R., Hsieh, M.-L., Chiang, J.-H., Chien, A., Hsieh, M.-S.: Emergency department visits and disease burden attributable to ambulatory care sensitive conditions in elderly adults. Sci. Rep. 9(1), 3811 (2019). https://doi.org/10.1038/s41598-019-40206-4

8. Health General Directorate: Health System Review - PORTUGAL (Final Report), April 2018. PHS - Portuguese Health System: https://www.sns.gov.pt/wp-content/uploads/2018/ 04/PortugalReviewReport_Printers_03April2018-2.pdf. Accessed 15 Jan 2019

9. Lesende, I., Crespo, L., Manzanares, S., et al.: Functional decline and associated factors in patients with multimorbidity at 8 months of follow-up in primary care: the functionality in pluripathological patients (FUNCIPLUR) longitudinal descriptive study. BMJ Open 8(7), e022377 (2018). https://doi.org/10.1136/bmjopen-2018-022377

10. World Health Organization: International Classification of Functioning, Disability and Health (ICF). https://www.who.int/classifications/icf/en/. Accessed 2 Mar 2018

11. Farias, N., Buchalla, C.M.: A classificação internacional de funcionalidade, incapacidade e saúde da organização mundial da saúde: conceitos, usos e perspectivas. Revista Brasileira de Epidemiologia 8(2), 187-193 (2005). https://doi.org/10.1590/S1415-790X2005000200011

12. Araujo, E.: Manual De Utilização da CIF Em Saúde Funcional: ANDREOLI (2011). ISBN 9788560416172. https://books.google.pt/books?id=pQO3uAAACAAJ. Accessed 2 Dezembro 2018

13. Lopes, M.J., Escoval, A., Pereira, D.G., Pereira, C.S., Carvalho, C., Fonseca, C.: Evaluation of elderly persons' functionality and care needs. Revista Latino-Americana de Enfermagem. 21(spe), 52-60 (2013). https://doi.org/10.1590/s0104-11692013000700008

14. Lopes, M.: A relação enfermeiro-doente como intervenção terapêutica: Formasau (2006). ISBN 972-8485-6-X. https://www.sinaisvitais.pt/index.php/livraria/a-relacao-enfermeirodoente-como-intervencao-terapeutica-detail. Accessed 14 Sept 2018

15. Fonseca, C., Lopes, M., Mendes, D., Parreira, P., Mónico, L., Marques, C.: Psychometric properties of the elderly nursing core set. In: García-Alonso, J., Fonseca, C. (eds.) IWoG 2018. CCIS, vol. 1016, pp. 143-153. Springer, Cham (2019). https://doi.org/10.1007/978-3030-16028-9_13. ISBN 978-3-030-16028-9

16. Lopes, M., Fonseca, C.: The construction of the elderly nursing core set. J. Aging Inovation 2(1), 121-131 (2013). http://journalofagingandinnovation.org/wp-content/uploads/9Nursing-elederly-core-set-.pdf

17. ULSBA: Unidade Local de Saúde do Baixo Alentejo. http://www.ulsba.min-saude.pt/. Accessed 29 Jan 2019

18. Scheaffer, R., Mendenhall, M., Ott, R., Gerow, K.: Elementary Survey Sampling: Cengage Learning (2012). ISBN 978-0840053619. https://www.amazon.com/Elementary-SurveySampling-Richard-Scheaffer/dp/0840053614. Accessed 15 Dec 2018

19. Marôco, J.: Análise de Equações Estruturais: Fundamentos teóricos, Software \& Aplicações. 2nd ed: Report Number (2014). ISBN 978-989-96763-3-6. http://www.reportnumber.pt/aee/. Accessed 12 Aug 2018

20. WHO: International Classification of Functioning, Disability and Health (ICF). https://www. who.int/classifications/icf/en/. Accessed 15 July 2019

21. WHO: How to use the ICF A Practical Manual for using the International Classification of Functioning, Disability and Health (ICF). https://www.who.int/classifications/icf/en/. Accessed 15 July 2019

22. Hair, J., Anderson, R., Tatham, R., Black, W.: Multivariate Data Analysis: Pearson Education Limited (2014). ISBN 978-0138132637 https://www.amazon.com/Multivariate-DataAnalysis-Joseph-Hair/dp/0138132631. Accessed 8 July 2018

23. Fonseca, C., Lista, A., Lopes, M., et al.: Dependence in self-care with comorbidity, indicators of nursing care and contributions to an ontology of aging: systematic review of the literature. Paper presented at the 2018 13th Iberian Conference on Information Systems and Technologies (CISTI), 13-16 June 2018. http://dx.doi.org/10.23919/CISTI.2018.8399236 
24. Abalo, E.M., Mensah, C.M., Agyemang-Duah, W., et al.: Geographical differences in perceived health status among older adults in Ghana: do gender and educational status matter? Gerontol. Geriatr. Med. 4, 1-9 (2018). https://doi.org/10.1177/2333721418796663

25. Davidson, P.M., DiGiacomo, M., McGrath, S.J.: The feminization of aging: how will this impact on health outcomes and services? Health Care Women Int. 32(12), 1031-1045 (2011). https://doi.org/10.1080/07399332.2011.610539

26. Kimberly, P.: Health Literacy: Improving Understanding of Discharge Instructions (9). Graduate Student Projects and Scholarship (9) (2017). https://digitalcommons.liberty.edu/nurse_ grad_proj_schol/9. Accessed 14 Sept 2018

"This is a post-peer-review, pre-copyedit version of an article published in Communications in Computer and Information Science book series (CCIS, volume 1185). The final authenticated version is available online at: https://doi.org/10.1007/978-3-030-41494-8_35". 